\title{
Protective effects of astragaloside IV against ovalbumin-induced allergic rhinitis are mediated by T-box protein expressed in $T$ cells/GATA-3 and forkhead box protein 3/retinoic acid-related orphan nuclear receptor $\gamma \mathrm{t}$
}

\author{
KEQIONG LI ${ }^{1,2^{*}}$, YI CHEN $^{3 *}$, RONG JIANG $^{3}$, DILONG CHEN ${ }^{3,5}$, HONG WANG $^{2}$, \\ WEI XIONG ${ }^{3}$, DANYANG LI ${ }^{3}$, ZEHONG LIU ${ }^{3}$, XIAOPENG $\mathrm{LI}^{3}, \mathrm{JING} \mathrm{LI}^{3}$ and KE YUAN ${ }^{4}$ \\ ${ }^{1}$ Chongqing Cancer Research Institute, Chongqing 400030; ${ }^{2}$ School of Public Health and Management, Chongqing \\ Medical University, Research Center for Medicine and Social Development, Innovation Center for Social Risk Governance \\ in Health; ${ }^{3}$ Laboratory of Stem Cells and Tissue Engineering, Department of Histology and Embryology, Chongqing \\ Medical University, Chongqing 400016; ${ }^{4}$ Department of Otorhinolaryngology, The Children's Hospital, Chongqing \\ Medical University, Chongqing 400010; ${ }^{5}$ Chongqing Three Gorges Medical College, Chongqing 404120, P.R. China
}

Received March 19, 2016; Accepted March 3, 2017

DOI: $10.3892 / \mathrm{mmr} .2017 .6685$

\begin{abstract}
O- $\beta$-D-xylopyranosyl-6-O- $\beta$-D-glucopyranos yl-cycloastragenol, or Astragaloside IV (AST), is one of the major active ingredients isolated from Astragalus membranaceous with distinct pharmacological effects, and possesses anti-inflammatory, immunoregulatory and antifibrotic properties. However, the effects of AST on allergic rhinitis remain to be elucidated. The present study aimed to examine the effects of AST on immunoglobulin (Ig) E-mediated allergic reactions in vivo, by using a mouse model of allergic rhinitis established via repetitive sensitization and intranasal challenge with ovalbumin (OVA). Intragastric administration of AST $(25 \mathrm{mg} / \mathrm{kg}$ or $50 \mathrm{mg} / \mathrm{kg}$ ) or dexamethasone (DEX; $3 \mathrm{mg} / \mathrm{kg}$ ) significantly alleviated the inflammatory response, nasal symptoms and mucosa remodeling, and decreased the serum levels of OVA-specific IgE in allergic mice. Furthermore, treatment with AST or DEX significantly suppressed the mRNA and protein expression levels of the transcription factor GATA-3
\end{abstract}

Correspondence to: Professor Jing Li, Laboratory of Stem Cells and Tissue Engineering, Department of Histology and Embryology, Chongqing Medical University, 1 Medical School Road, Yuzhong, Chongqing 400016, P.R. China

E-mail: 569258455@qq.com

Dr Ke Yuan, Department of Otorhinolaryngology, The Children's Hospital, Chongqing Medical University, 136 Zhongshan Road, Yuzhong, Chongqing 400010, P.R. China

E-mail: 1219629801@qq.com

${ }^{*}$ Contributed equally

Key words: allergic rhinitis, astragaloside IV, forkhead box protein 3, T-box protein expressed in T cells, GATA-3, forkhead box protein 3/retinoic acid-related orphan nuclear receptor $\gamma \mathrm{t}$ and retinoic acid receptor-related orphan nuclear receptor (ROR) $\gamma t$ in tissue samples isolated from the spleen and nasal mucosa of mice with allergic rhinitis. Conversely, mRNA and protein expression levels of T-box protein expressed in T cells (T-bet) and forkhead box protein 3 (Foxp3) were upregulated in the spleen and nasal mucosa of mice with allergic rhinitis following treatment with AST or DEX, and spleen protein levels of signal transducer and activator of transcription 3 followed a similar trend. In addition, treatment with AST was associated with fewer adverse events compared with treatment with DEX. The present results suggested that treatment with AST may attenuate OVA-induced allergic rhinitis via regulating the expression of the transcription factors GATA-3, ROR $\gamma$ t, T-bet and Foxp3, which commit T helper cells to the Th1 phenotype. Therefore, AST may represent an alternative therapeutic approach for the treatment of patients with allergic rhinitis.

\section{Introduction}

Allergic rhinitis is a type of nasal inflammation which occurs when the immune system overreacts to inhaled allergens, and is a frequent and serious public health concern. Anti-allergic and antihistamine agents are commonly used in the treatment of allergic rhinitis; however, their effects are transient as they are able to suppress only the symptoms of the inflammatory response (1). Therefore, the development of novel therapeutic strategies that target the pathogenesis of the disorder are required for the treatment of allergic rhinitis.

During an allergic response, the activation of $\mathrm{T}$ helper (Th)1 and Th2 cells appears to be mutually antagonistic. Under physiological conditions, Th1 and Th2 populations exist in equilibrium and cross-regulate each other, and the Th1/Th2 balance has been suggested to be necessary for the maintenance of immune homeostasis (2,3). GATA-3 is a transcription factor revealed to be specifically expressed in Th2 cells, whereas 
T-box protein expressed in T cells (T-bet) is a transcription factor specifically expressed in Th1 cells. GATA-3 and T-bet have been reported to modulate gene expression during $\mathrm{T}$ cell differentiation, thus serving a critical role in the development of Th1 and Th2 lineages (4,5). However, the molecular mechanisms underlying allergic rhinitis are complex and involve other pathways apart from an aberrant Th2 response. Regulatory $\mathrm{T}$ (Treg) cells have been suggested to serve critical roles in the maintenance of immune homeostasis. Treg cells have been reported to inhibit the proliferation and activation of conventional effector $\mathrm{T}$ cells in a cell contact-dependent manner, either directly or via acting on antigen-presenting cells (6). The forkhead family transcription factor Foxp3 plays a key role on Treg cells in inhibition of tissue inflammation reaction and regulate the body's immune stability (7). Th17 cells has the opposite effect of Treg cells, while ROR $\gamma \mathrm{t}$ is a splice variant of ROR, which has been identified as an essential factor during Th17 cellular differentiation $(8,9)$. However, the induction of ROR $\gamma \mathrm{t}$ has been reported to be dependent on the activity of STAT-3. ROR $\gamma$ t and STAT-3 may collaboratively regulate the transcriptional profile of Th17 cells (10).

Astragalus membranaceus is a herb with a long history of use in traditional Chinese medicine for the treatment of allergic rhinitis (11). 3-O- $\beta$-D-xylopyranosyl-6-O- $\beta$-D-glucopyranosy 1-cycloastragenol, or astragaloside IV (AST), which belongs to the chemical class of saponins, is one of the primary active compounds isolated from Astragalus membranaceus roots with distinct pharmacological effects, and has anti-inflammatory, immunoregulatory and antifibrotic properties $(12,13)$. It has previously been demonstrated that AST markedly inhibits airway inflammation and has profound immunoregulatory effects in vivo (14). In addition, AST has been reported to exert neuro- and cardioprotective effects during cerebral and myocardial ischemic events, which have been attributed to its anti-inflammatory, antioxidative, antithrombotic, vasodilatory and immunoregulatory properties $(15,16)$. Therefore, the present study aimed to investigate whether AST exhibited regulatory effects on allergic responses in vivo. In addition, it aimed to examine the molecular mechanisms underlying the putative protective effects of AST against allergic rhinitis, potentially involving regulation of the of Th1/Th2 and Treg cellular responses.

\section{Materials and methods}

Reagents. AST (purity $>95 \%$ ) was obtained from the National Institutes for Food and Drug Control (Beijing, China) and was suspended in a $1 \%$ carboxymethylcellulose solution. Dexamethasone (DEX) was purchased from Shenyang Comeboard Technology Co.,Ltd(Shenyang,China). Ovalbumin (OVA, fraction V) was purchased from Sigma-Aldrich; Merck KGaA (Darmstadt, Germany). Aluminium hydroxide [Al $\left.(\mathrm{OH})_{3}\right]$ was obtained from Pierce; Thermo Fisher Scientific, Inc. (Waltham, MA, USA). Immunoglobulin (Ig)E (cat no. SEA545Ra) and IgG (cat no. HEA544Ra) ELISA kits were purchased from Cloud-Clone Corp. (Houston, TX, USA). Anti-GATA-3 (cat no. 5852T), anti-T-box protein expressed in $\mathrm{T}$ cells (T-bet; cat no. 13232T), anti-signal transducer and activator of transcription (STAT)-3 (cat no. 12640S) and anti- $\beta$-actin antibody (cat no. 3700S) monoclonal antibodies were obtained from Cell Signaling Technology, Inc. (Danvers, MA, USA). An anti-forkhead box protein 3 (Foxp3; cat no. ab20034) antibody was purchased from Abcam (Cambridge, MA, USA).

Animals. A total of 25 male and 25 female BALB/c mice (age: 6-8 weeks; weight, 15-20 g) were purchased from the Laboratory Animal Center of Chongqing Medical University (Chongqing, China), and were maintained in horizontal laminar flow cabinets and provided with free access to sterile food and water in a specific pathogen-free facility (temperature, $18-29^{\circ} \mathrm{C} ; 12 / 12 \mathrm{~h}$ light/dark cycles). Mice were randomly assigned to the following five groups ( $\mathrm{n}=10 \mathrm{mice} / \mathrm{group}$ ): Normal control (saline only), OVA-induced allergic rhinitis (OVA), AST (25 mg/kg and $50 \mathrm{mg} / \mathrm{kg} ; \mathrm{n}=10 \mathrm{mice} / \mathrm{sub}$-group) and DEX (3 mg/kg). The 25 and $50 \mathrm{mg} / \mathrm{kg}$ doses of AST were selected based on previous studies (17).

The present study was conducted in accordance with the internationally accepted principles for laboratory animal use and care, as outlined in the European Commission guidelines (EEC Directive of 1986; 86/609/EEC). The experimental procedures were approved by the Animal Ethics Committee of Chongqing Medical University.

Allergic rhinitis model and AST administration. Mice in the OVA, AST and DEX groups were administered intraperitoneally with $0.5 \mathrm{mg} / \mathrm{ml} \mathrm{OVA}$ and $20 \mathrm{mg} / \mathrm{ml} \mathrm{Al}(\mathrm{OH})_{3}$ in saline, at a dose of $0.2 \mathrm{ml} / \mathrm{mouse}$ (sensitization), as previously described (18). Sensitization was repeated three times at weekly intervals (days 0,7 and 14), and was followed by daily administration of OVA solution (40 $\mathrm{mg} / \mathrm{ml}$ in saline) into the nostrils ( $0.02 \mathrm{ml} / \mathrm{mouse}$ ), on days 21-42 (OVA challenge). Mice in the AST and DEX treatment groups were administered intragastrically with AST (25 or $50 \mathrm{mg} / \mathrm{kg}$ ) or DEX ( $3 \mathrm{mg} / \mathrm{kg}$ ) daily for 3 weeks, $30 \mathrm{~min}$ prior to the OVA challenge. Mice in the normal group were administered only with the last intranasal OVA challenge on day 42. Nasal symptoms were evaluated via counting the number of sneezes for $10 \mathrm{~min}$ immediately following the last OVA intranasal challenge.

Weight and spleen/hepatic index measurements. The weight of each mouse was measured weekly using an electronic scale. A total of $48 \mathrm{~h}$ following the last treatment, all mice were weighed, anesthetized with ether and sacrificed. The spleen and liver were harvested and used for further analysis. The spleen and hepatic indices were calculated according to the following formula: Spleen/hepatic index=spleen/liver weight $(\mu \mathrm{g}) /$ body weight $(\mathrm{g}) \times 10$, as previously described (19).

ELISA. A total of $48 \mathrm{~h}$ following the last treatment, mice were anesthetized with ether and sacrificed. Blood samples were collected from the orbital sinus. Samples were kept standing for $30 \mathrm{~min}$ at room temperature, were centrifuged at 3,000 x g for $10 \mathrm{~min}$ at room temperature and the serum was isolated. Concentrations of OVA-specific IgE and total IgG were evaluated using the appropriate ELISA kits.

Hematoxylin-eosin (HE) and immunohistochemical staining. A total of $48 \mathrm{~h}$ following the last treatment, mice were sacrificed and their heads and spleens were harvested and 
immersed in $4 \%$ neutral-buffered formalin at room temperature for 7 days. Following fixation, heads were decalcified in $5 \%$ formic acid at room temperature for 6 days. Subsequently, the heads and spleens were trimmed, embedded in paraffin and sectioned coronally at a thickness of $4 \mu \mathrm{m}$ for $\mathrm{HE}$ and immunohistochemical staining. For the immunohistochemical detection of GATA-3, T-bet and Foxp3, slides were placed in $0.01 \mathrm{M}$ citric buffer $\left(\mathrm{pH} 6.0\right.$ ) and autoclaved at $121^{\circ} \mathrm{C}$ for $20 \mathrm{~min}$. Sections were blocked with mountain goat serum (Hyclone; GE Healthcare Life Sciences, Logan, UT, USA) at room temperature for $20 \mathrm{~min}$ and incubated with anti-GATA-3 $(1: 1,00)$, anti-T-bet $(1: 1,00)$ and anti-Foxp3 $(1: 2,00)$ polyclonal antibodies at $4^{\circ} \mathrm{C}$ for $12 \mathrm{~h}$. Subsequently, sections were washed, incubated with an anti-mouse horseradish peroxidase (HRP) -conjugated IgG secondary antibody (1:1,000; Beyotime Institute of Biotechnology, Haimen, China; cat no. A0216) at $37^{\circ} \mathrm{C}$ for $1 \mathrm{~h}$ and stained with 3,3'-diaminobenzidine. Numbers of eosinophils infiltrating the nasal mucosa were counted in HE-stained sections in 3 randomly selected fields under a x400 magnification. Stained sections were observed under a Leica DM2500 optical microscope (Leica Microsystems, Inc., Buffalo Grove, IL, USA) and photomicrographs were captured.

Reverse transcription-quantitative polymerase chain reaction $(R T-q P C R)$. Total RNA was extracted from spleen tissue samples using TRIzol ${ }^{\circledR}$ reagent (Invitrogen; Thermo Fisher Scientific, Inc.) and reverse transcribed into cDNA using the High Capacity cDNA Reverse Transcription kit (Thermo Fisher Scientific, Inc.) and an oligo (dT) primer (Thermo Fisher Scientific, Inc.), according to the manufacturer's protocol. The reaction volume was $8 \mu \mathrm{l}(5 \mathrm{X}$ reaction buffer $4 \mu \mathrm{l}$, dNTP mix $1 \mu \mathrm{l}$, Rnase Inhibitor $0.5 \mu \mathrm{l}$, Rnase free $\mathrm{H}_{2} \mathrm{O} 0.5 \mu \mathrm{l}$, M-MLV enzyme $2 \mu \mathrm{l}$ ). Amplification conditions were as follows: at $30^{\circ} \mathrm{C}$ for $10 \mathrm{~min}$, at $42^{\circ} \mathrm{C}$ for $60 \mathrm{~min}$ and at $70^{\circ} \mathrm{C}$ for $15 \mathrm{~min}$. Primer sequences for murine GATA-3, T-bet, retinoic acid receptor-related orphan nuclear receptor (ROR) $\gamma \mathrm{t}$, Foxp3 and $\beta$-actin, which served as the internal control, are presented in Table I. The cDNA products were used as templates for qPCR. The CFX96 ${ }^{\mathrm{TM}}$ Real-Time PCR detection system (Bio-Rad Laboratories, Inc., Hercules, CA, USA) was used for analysis with SYBR ${ }^{\circledR}$ Premix Ex Taq ${ }^{\mathrm{TM}}$ (Takara Biotechnology Co., Ltd., Dalian, China). The reaction was performed in a total volume of $25 \mu \mathrm{l}\left(\mathrm{SYBR}^{\circledR}\right.$ Premix Ex Taq ${ }^{\mathrm{TM}} 2 \mathrm{X} 12.5 \mu \mathrm{l}$, forward primer $(10 \mu \mathrm{mol} / \mathrm{l}) 1 \mu \mathrm{l}$, reverse primer $(10 \mu \mathrm{mol} / \mathrm{l}) 1 \mu \mathrm{l}, \mathrm{cDNA}$ $2 \mu \mathrm{l}, \mathrm{dd}_{2} \mathrm{O} 8.5 \mu \mathrm{l}$ ) with the following thermocycling conditions: Initial denaturation at $5^{\circ} \mathrm{C}$ for $2 \mathrm{~min}$, followed by $10 \mathrm{~min}$ at $95^{\circ} \mathrm{C}, 40$ cycles of annealing at $95^{\circ} \mathrm{C}$ for $15 \mathrm{sec}$ followed by extension at $60^{\circ} \mathrm{C}$ for $1 \mathrm{~min}$. Gene expression was quantified using the comparative $2^{-\Delta \Delta \mathrm{Cq}}$ method and normalized to $\beta$-actin (20).

Western blot assay. Spleen tissue was dissected and sonicated in T-PER ${ }^{\mathrm{TM}}$ Tissue Protein Extraction Reagent (Thermo Fisher Scientific, Inc.) containing protease cocktail (Beyotime Institute of Biotechnology) on ice. The lysates were centrifuged at $10,000 \times \mathrm{g}$ for $10 \mathrm{~min}$ at $4^{\circ} \mathrm{C}$. Protein concentration was determined using a BCA assay kit (Beyotime Institute of Biotechnology). Equal amounts of extracted protein samples $(50 \mu \mathrm{g})$ were separated by $10 \%$ SDS-PAGE and transferred onto polyvinylidene difluoride membranes. The membranes
Table I. Primer sequences used for reverse transcription-quantitative polymerase chain reaction.

\begin{tabular}{ll}
\hline Gene & \multicolumn{1}{c}{ Sequence (5'-3') } \\
\hline GATA-3 & F:ACAGAAGGCAGGGAGTGTGT \\
& R: GGTAGAGTCCGCAGGCATT \\
T-bet & F: TACAACAGCCAGCCAAACAG \\
& R: CACCCTTCAAACCCTTCCTC \\
ROR $\gamma \mathrm{t}$ & F: TGCGACTGGAGGACCTTCTA \\
& R: TCACCTCCTCCCGTGAAAAG \\
Foxp3 & F: GCCCATCCAATAAACTGTGG \\
& R: GTATCCGCTTCTCCTGCTG \\
$\beta$-actin & F: GAGACCTTCAACACCCCAGC \\
& R: ATGTCACGCACGATTTCCC
\end{tabular}

T-bet, T-box protein expressed in $\mathrm{T}$ cells; ROR, retinoic acid receptor-related orphan nuclear receptor; Foxp, forkhead box protein; F, forward; R, reverse.

were blocked with $5 \%$ non-fat dry milk at $37^{\circ} \mathrm{C}$ for $1 \mathrm{~h}$ and incubated overnight at $4^{\circ} \mathrm{C}$ with the following primary antibodies: Anti-GATA-3 (1:1,000), anti-T-bet $(1: 1,000)$, anti-STAT-3 $(1: 1,000)$, anti-Foxp3 $(1: 2,000)$ and anti- $\beta$-actin $(1: 5,000)$. Subsequently, membranes were incubated with HRP-conjugated goat anti-rabbit IgG (cat no. A0208) or goat anti-mouse IgG (cat no. A0258) secondary antibodies (1:2,000; Beyotime Institute of Biotechnology) at $37^{\circ} \mathrm{C}$ for $2 \mathrm{~h}$. Protein bands were visualized using the Immun-Star ${ }^{\mathrm{TM}}$ HRP Chemiluminescent kit (Bio-Rad Laboratories, Inc.) and the Molecular Imager ${ }^{\circledR}$ VersaDoc $^{\mathrm{TM}}$ MP imaging system (Bio-Rad Laboratories, Inc.). $\beta$-actin served as the loading control.

Statistical analysis. The statistical significance of the difference between groups was assessed by one-way analysis of variance followed by a post hoc Dunnett's test for multiple comparisons. Data are expressed as the mean \pm standard deviation of three independent experiments. $\mathrm{P}<0.05$ was considered to indicate a statistically significant difference. Statistical analysis was performed using the SPSS software version 22.0 (IBM SPSS, Armonk, NY, USA).

\section{Results}

AST administration alleviates allergic rhinitis symptoms in mice. The putative protective effects of AST against allergic rhinitis were examined in allergic rhinitis mice, following intragastric administration of AST ( 25 or $50 \mathrm{mg} / \mathrm{kg}$ ), DEX ( $3 \mathrm{mg} / \mathrm{kg}$ ) or saline (control). Mice in the OVA model group exhibited a marked increase in the number of sneezes $(31.5 \pm 2.04$ counts $/ 10 \mathrm{~min})$ compared with in the normal, non-sensitized group that received only the last challenge immediately prior to assessment $(8.0 \pm 2.7$ counts $/ 10$ min; $\mathrm{P}<0.05$; Fig. 1A). Sneeze counts of AST-treated allergic $(17.0 \pm 2.6$ counts $/ 10 \mathrm{~min}, 25 \mathrm{mg} / \mathrm{kg}$ AST; $17.3 \pm 3.5$ counts/10 min, $50 \mathrm{mg} / \mathrm{kg} \mathrm{AST})$ and DEX-treated mice $(18.5 \pm 3.0$ counts $/ 10 \mathrm{~min})$ were significantly reduced compared with mice in the OVA model group $(\mathrm{P}<0.05$; Fig. 1A). These 
A

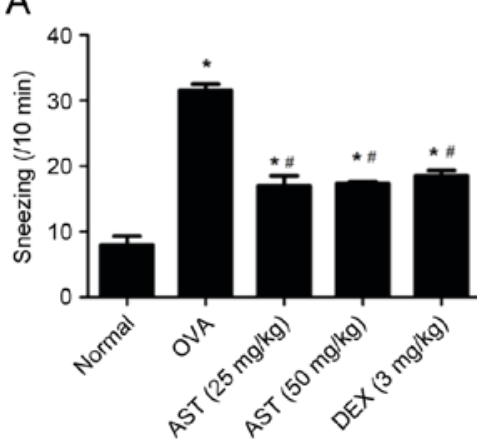

B

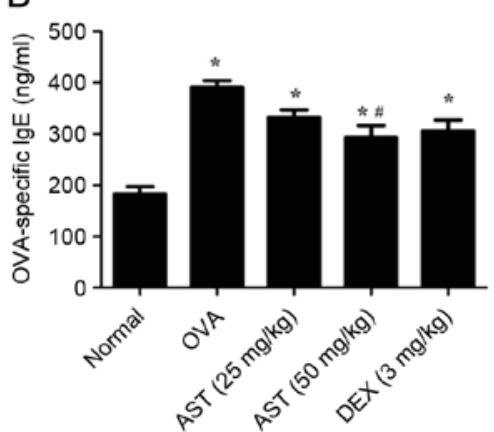

C

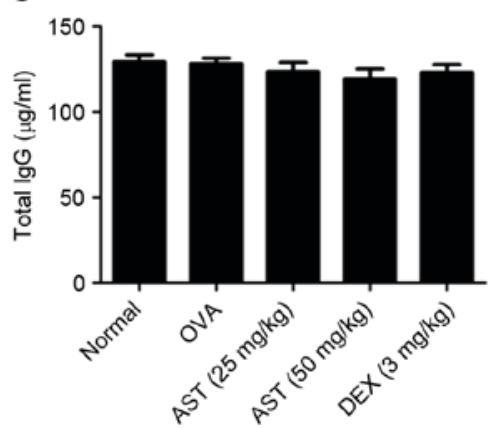

Figure 1. Effects of AST administration on OVA-induced allergic response and Ig concentrations. (A) Sneezes were counted for 10 min following the last OVA challenge. Serum concentrations of (B) OVA-specific IgE and (C) total IgG were evaluated using ELISA. Data are expressed as the mean \pm standard deviation. ${ }^{*} \mathrm{P}<0.05$ vs. normal; " $\mathrm{P}<0.05$ vs. OVA. AST, Astragaloside IV; OVA, ovalbumin; Ig, immunoglobulin; DEX, dexamethasone; DEX, dexamethasone.

results suggested that treatment with AST may ameliorate the symptoms associated with allergic rhinitis.

AST administration decreases serum IgE levels. OVA-specific $\mathrm{IgE}$ and $\mathrm{IgG}$ levels in mouse serum samples were examined by ELISA. OVA-specific IgE serum levels were significantly increased in mice with OVA-induced allergic rhinitis compared with control mice (Fig. 1B). However, treatment with $50 \mathrm{mg} / \mathrm{kg}$ AST reversed this effect. Conversely, IgG levels in mouse serum samples remained unaffected, regardless of the treatment administered (Fig. 1C).

Histopathological alterations in nasal mucosa and spleen. Morphological alterations in nasal mucosal and spleen tissue samples of allergic mice were investigated using HE staining. Nasal mucosal tissue isolated from allergic mice exhibited prominent alterations, including eosinophil infiltration, blood vessel sprouting, gland hyperplasia and enlargement, and mucosal remodeling. In addition, the nasal epithelium became multilayered (Fig. 2A). Spleen tissue isolated from allergic mice was characterized by splenic corpuscle proliferation (Fig. 2B). Notably, the administration of AST or DEX appeared to prevent the infiltration of eosinophils in the submucosa, the acidophilic alterations and the development of fibrosis. Furthermore, AST and DEX appeared to attenuate splenic corpuscle proliferation (Fig. 2B). These findings suggested that AST administration may alleviate allergic responses in OVA-challenged mice.

AST downregulates GATA-3 and upregulates T-bet mRNA and protein expression levels in allergic mice. It has previously been reported that Th2-type cytokines, as well as the GATA-3/T-bet expression ratio in lung tissue isolated from allergic mice were affected following Astragalus membranaceus administration (21) Therefore, it may be hypothesized that the mechanisms underlying the antiallergic effects of AST involve the regulation of transcription factors, including T-bet and GATA-3, during Th1 and Th2 cellular differentiation. The present study used immunohistochemistry, RT-qPCR and western blot analysis to investigate the expression of GATA-3 and T-bet in nasal mucosal and spleen tissue of allergic mice. Immunohistochemical results demonstrated that GATA-3 expression levels were downregulated in nasal mucosal
(Fig. 3A) and spleen (Fig. 3B) tissue samples following AST or DEX administration, whereas T-bet expression levels were upregulated (Fig. 4). Similar expression alterations for GATA-3 and T-bet were observed at the protein (Fig. 5A) and mRNA (Fig. 5B) level, as determined by western blotting and RT-qPCR, respectively. These findings suggested that treatment with AST may downregulate the expression of GATA-3 and upregulate the expression of T-bet during allergic responses in vivo.

Effects of AST on Foxp3, ROR $\gamma$ t and STAT-3. The expression of the inflammation-associated proteins Foxp3, ROR $\gamma \mathrm{t}$ and STAT-3 in mouse spleen tissue was altered following AST and DEX administration. Mice in the OVA model group demonstrated decreased Foxp3 protein (Fig. 5A) and mRNA (Fig. 5B) expression levels compared with the normal group. Notably, AST and DEX administration upregulated Foxp3 protein and mRNA expression levels compared with the OVA model group (Fig. 5A and B, respectively). Similar effects were observed via immunohistochemical staining (Fig. 6). Conversely, protein expression levels of STAT-3 and mRNA expression levels of ROR $\gamma t$ appeared to be upregulated in allergic mice; however, treatment with AST and DEX ameliorated this effect (Fig. 5A and $\mathrm{B}$, respectively).

Adverse events associated with DEX administration. The body weight of mice from all groups was measured from days 1-42. The results demonstrated that mice in the DEX group started to lose weight from day 29 (Fig. 7A). Following long-term therapy with DEX (42 days), the weight and spleen index of mice in the DEX group were significantly reduced $(\mathrm{P}<0.05$ vs. the normal group; Fig. 7B and $\mathrm{C}$, respectively). However, DEX administration exerted no effects on the liver index (Fig. 7D).

\section{Discussion}

Allergic rhinitis is one of the most common allergies in children and young individuals, and poses a serious public health concern (22). A 2011 epidemiological investigation reported that in western China, the prevalence of allergic rhinitis was $30.3 \%$ (Nanning), 37.9\% (Urumqi), 34.3\% (Chengdu) and $32.30 \%$ (Chongqing) (23). Current treatment strategies aimed 
A
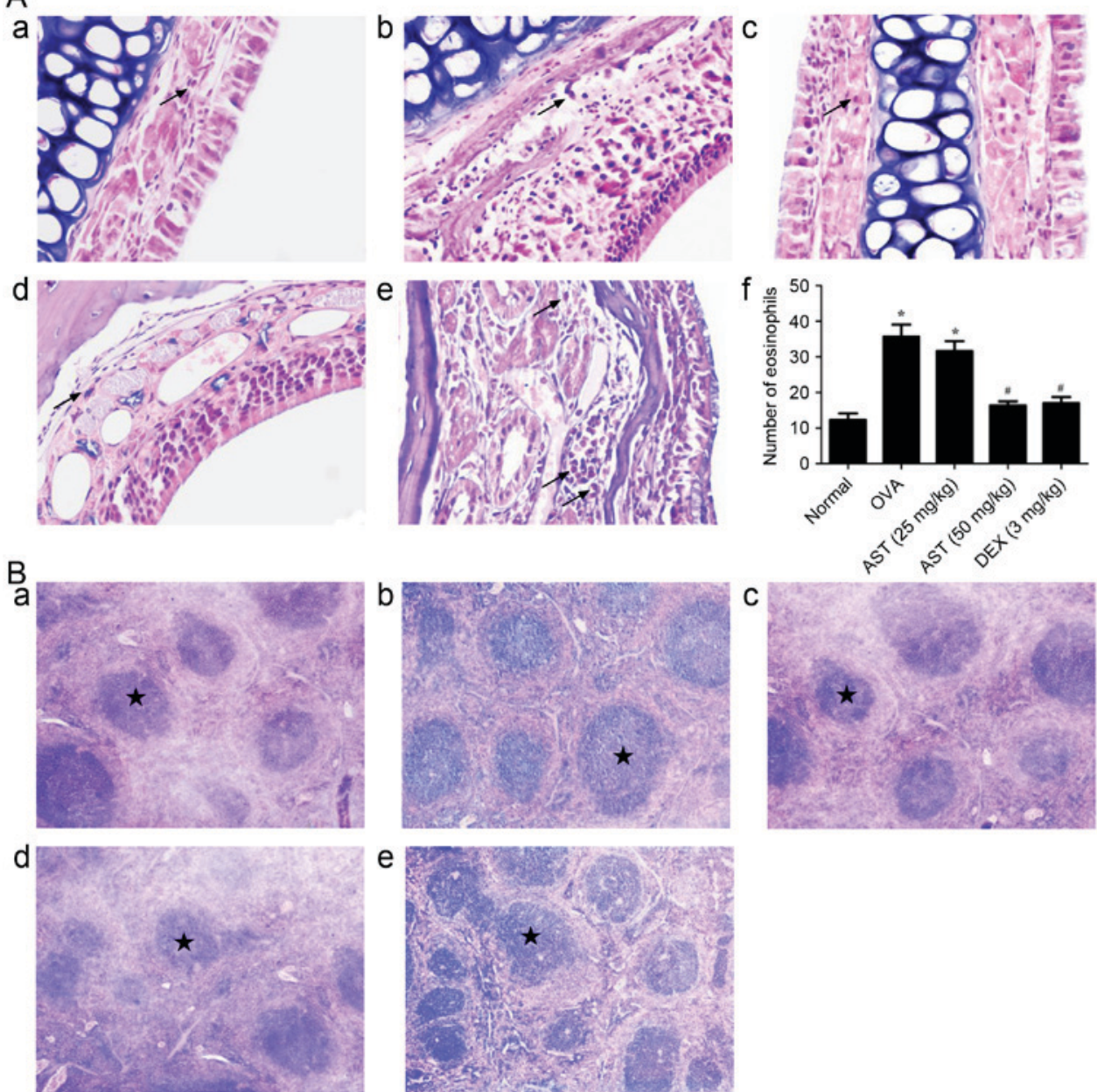

Figure 2. Morphological alterations following OVA sensitization and AST administration in mouse nasal mucosa and spleens. (A) Representative photomicrographs of the numbers of eosinophils infiltrating the nasal mucosa in the (a) normal, (b) $25 \mathrm{mg} / \mathrm{kg} \mathrm{AST}$, (c) $50 \mathrm{mg} / \mathrm{kg}$ AST, (d) DEX and (e) OVA groups, and (f) quantification. Data are expressed as the mean \pm standard deviation. Arrows indicate the presence of eosinophils. "P $<0.05$ vs. the normal group; ${ }^{*} \mathrm{P}<0.05$ vs. the OVA model group. (B) Representative photomicrographs of mouse spleen tissue in the (a) normal, (b) $25 \mathrm{mg} / \mathrm{kg}$ AST, (c) $50 \mathrm{mg} / \mathrm{kg} \mathrm{AST}$, (d) DEX and (e) OVA groups. Stars indicate the location of the splenic corpuscle. Magnification, x400. OVA, ovalbumin; AST, Astragaloside IV; DEX, dexamethasone.

at allergic disorders include leukotriene inhibitors, mast cell stabilizers and $\beta_{2}$ adrenergic agonists, which have been associated with serious adverse events (24-26). Therefore, the development of novel complementary and alternative therapeutic strategies for the treatment of allergic disorders is required. Treatments used in traditional Chinese medicine include various natural products, including AST (11), and may have potential as alternative therapeutic approaches for the management of allergic rhinitis.

AST has previously been reported to suppress interleukin (IL)-13 and tumor necrosis factor- $\alpha$ levels in the supernatants of D10.G4.1 Th2 lymphocyte cultures in vitro, and inhibited GATA-3 expression (27). The present study used an OVA-induced mouse model of allergic rhinitis to assess the putative anti-inflammatory effects of AST and investigate the molecular mechanisms underlying its actions on allergic rhinitis. The present results suggested that AST may alleviate allergic symptoms, as it was demonstrated to inhibit eosinophilic infiltration, to suppress the production of OVA-specific IgE, and to attenuate splenic corpuscle proliferation. The recruitment of eosinophils in allergic rhinitis has been suggested to be initiated by Th2-type cytokines (28).
The present results demonstrated that eosinophil counts were decreased in AST-treated allergic mice compared with untreated controls. The effects of AST in preventing eosinophilic infiltration in the nasal mucosa may be attributed to the inhibition of Th2-type cytokines. Class-switch recombination has been reported to occur in restricted areas, including the germinal center of lymph nodes, and B cells have been demonstrated to undergo class switching to $\mathrm{IgE}$ production in nasal mucosa following allergen exposure (29). However, it is possible that IgE production in the spleen and lymphatic system may differ during Th2-based immune responses induced by OVA immunization in mice. OVA-specific IgE is predominantly produced in lymphoid tissue, but not in the spleen (30). The present results revealed that AST suppressed the proliferation of splenic corpuscles and the production of OVA-specific IgE, thus suggesting that AST may regulate the production of OVA-specific IgEs in the spleen.

Potentiated Th2-mediated responses and impaired Th1 activation have been reported to mediate allergic inflammatory responses $(31,32)$. GATA-3 belongs to the GATA family of transcription factors, and naive cluster of differentiation (CD) $4^{+} \mathrm{T}$ cells express low levels of GATA-3 mRNA; 

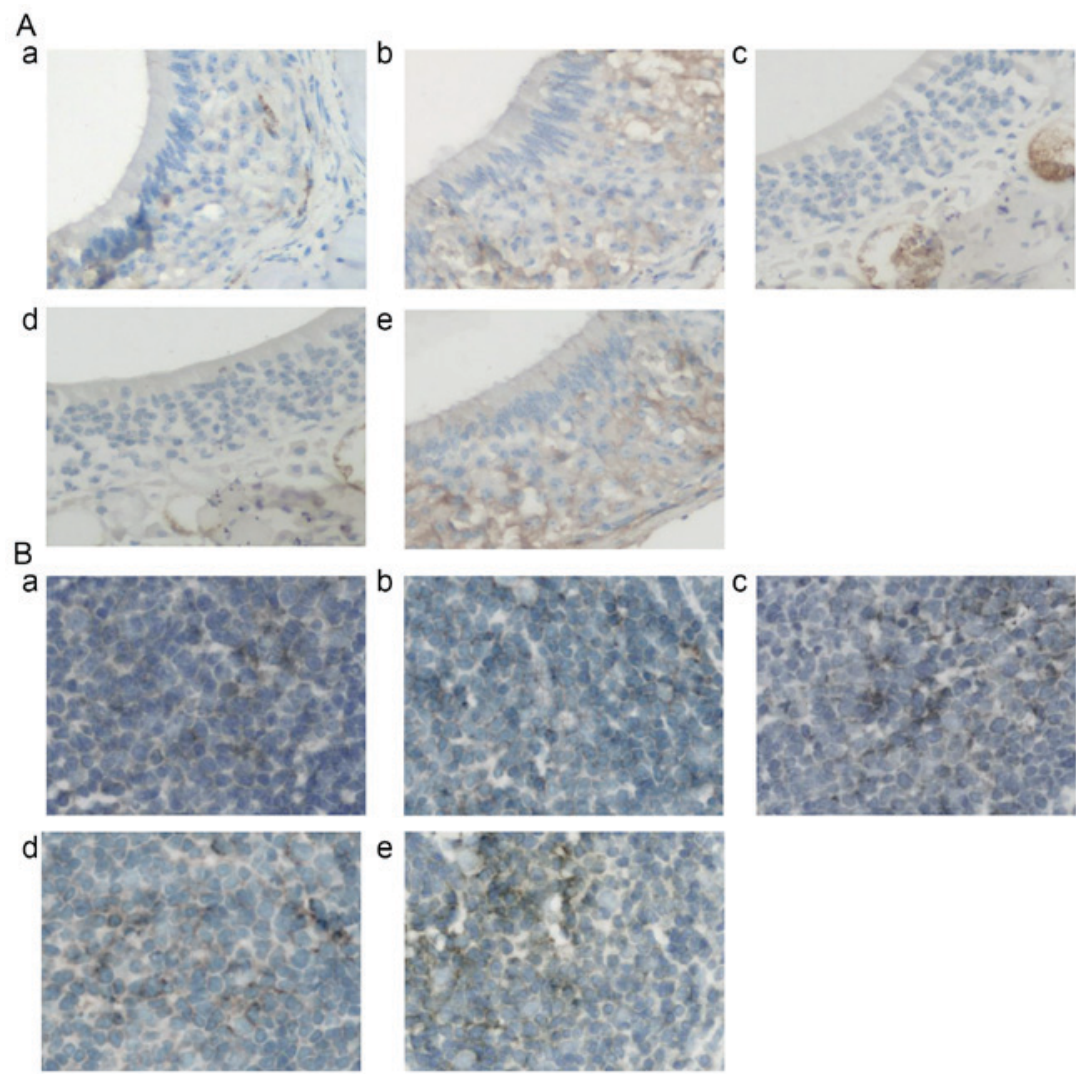

Figure 3. Effects of AST administration on GATA-3 protein expression. (A) Representative photomicrographs of GATA-3 protein expression in nasal mucosa tissue samples in the (a) normal, (b) $25 \mathrm{mg} / \mathrm{kg}$ AST, (c) $50 \mathrm{mg} / \mathrm{kg}$ AST, (d) DEX and (e) OVA groups. (B) Representative photomicrographs of mouse spleen tissue in the (a) normal, (b) $25 \mathrm{mg} / \mathrm{kg}$ AST, (c) $50 \mathrm{mg} / \mathrm{kg}$ AST, (d) DEX and (e) OVA groups. Magnification, x400. AST, Astragaloside IV; OVA, ovalbumin; DEX, dexamethasone.
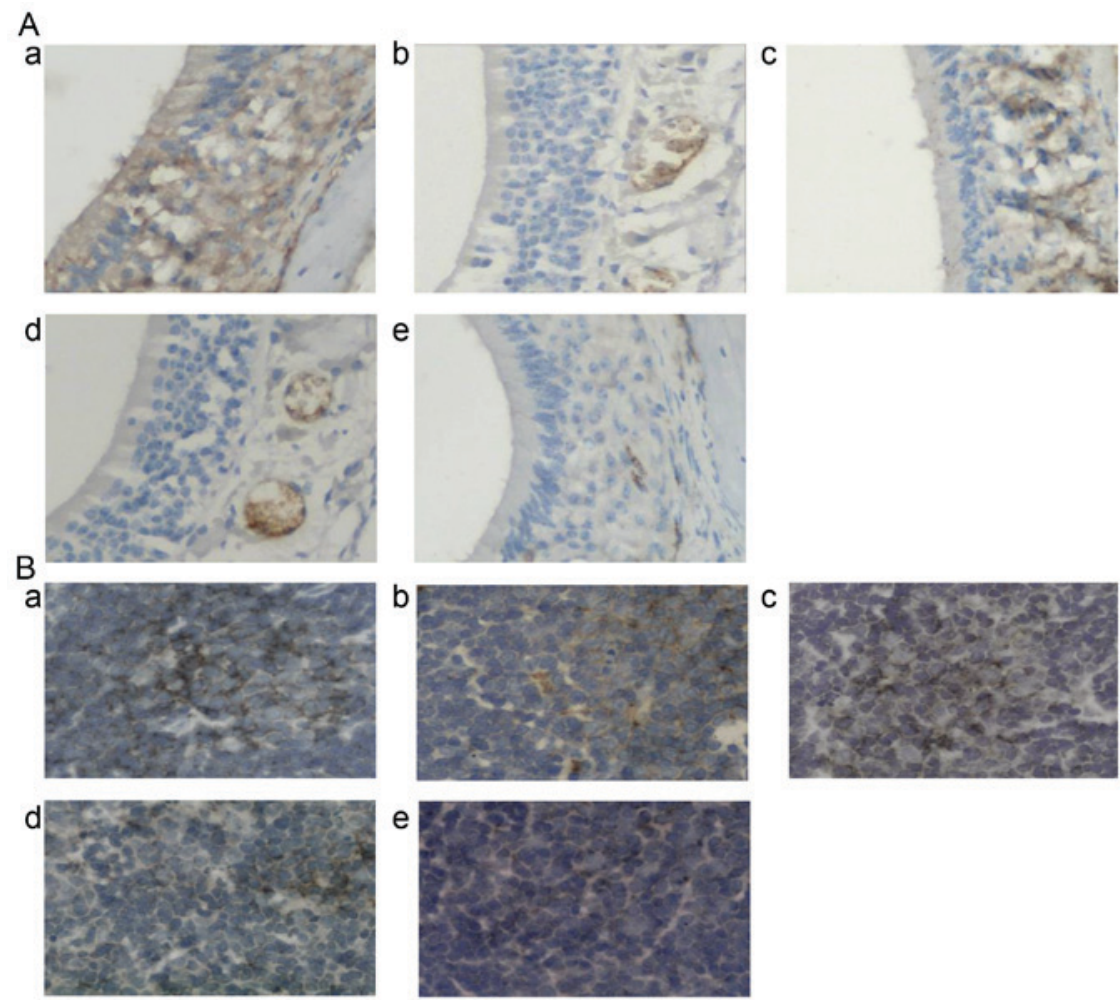

Figure 4. Effects of AST administration on T-bet protein expression. (A) Representative photomicrographs of T-bet protein expression in nasal mucosa tissue samples in the (a) normal, (b) $25 \mathrm{mg} / \mathrm{kg}$ AST, (c) $50 \mathrm{mg} / \mathrm{kg}$ AST, (d) DEX and (e) OVA groups. (B) Representative photomicrographs of mouse spleen tissue in the (a) normal, (b) $25 \mathrm{mg} / \mathrm{kg}$ AST, (c) $50 \mathrm{mg} / \mathrm{kg}$ AST, (d) DEX and (e) OVA groups. Magnification, x400. AST, Astragaloside IV; OVA, ovalbumin; DEX, dexamethasone; T-bet, T-box protein expressed in T cells. 
A

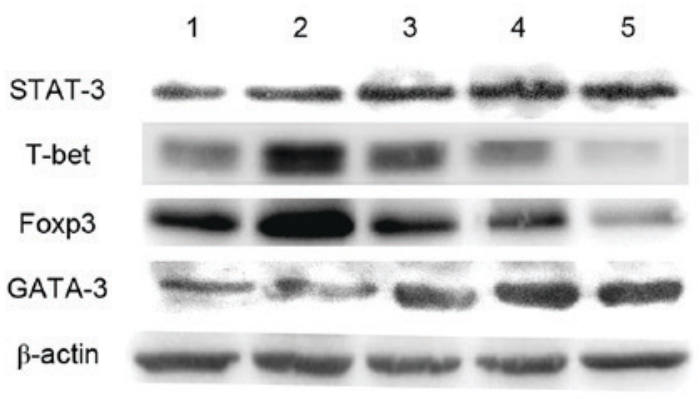

B

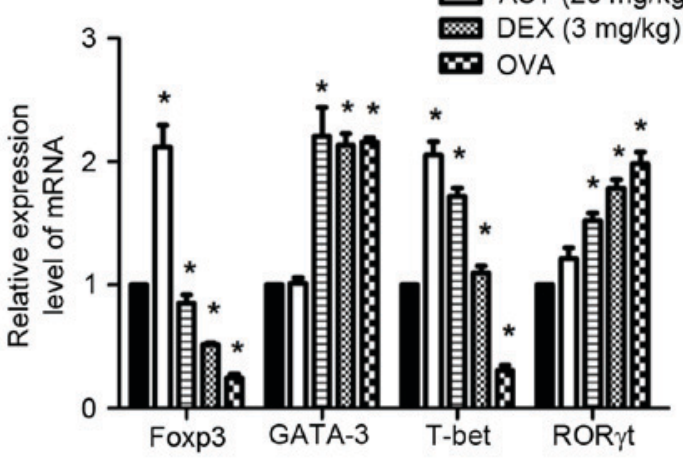

Figure 5. Effects of AST administration on factors implicated in T helper cell differentiation. (A) Representative western blot images and (B) reverse transcription-quantitative polymerase chain reaction analysis of GATA-3, T-bet, Foxp3 and STAT-3 protein and mRNA expression levels, respectively, in spleen tissue samples. $\beta$-actin served as an internal control. Data are expressed as the mean \pm standard deviation. ${ }^{*} \mathrm{P}<0.05$ vs. normal; ${ }^{\#} \mathrm{P}<0.05$ vs. OVA model. AST, Astragaloside IV; T-bet, T-box protein expressed in T cells; Foxp, forkhead box protein; STAT, signal transducer and activator of transcription; OVA, ovalbumin; DEX, dexamethasone; ROR, retinoic acid receptor-related orphan nuclear receptor.
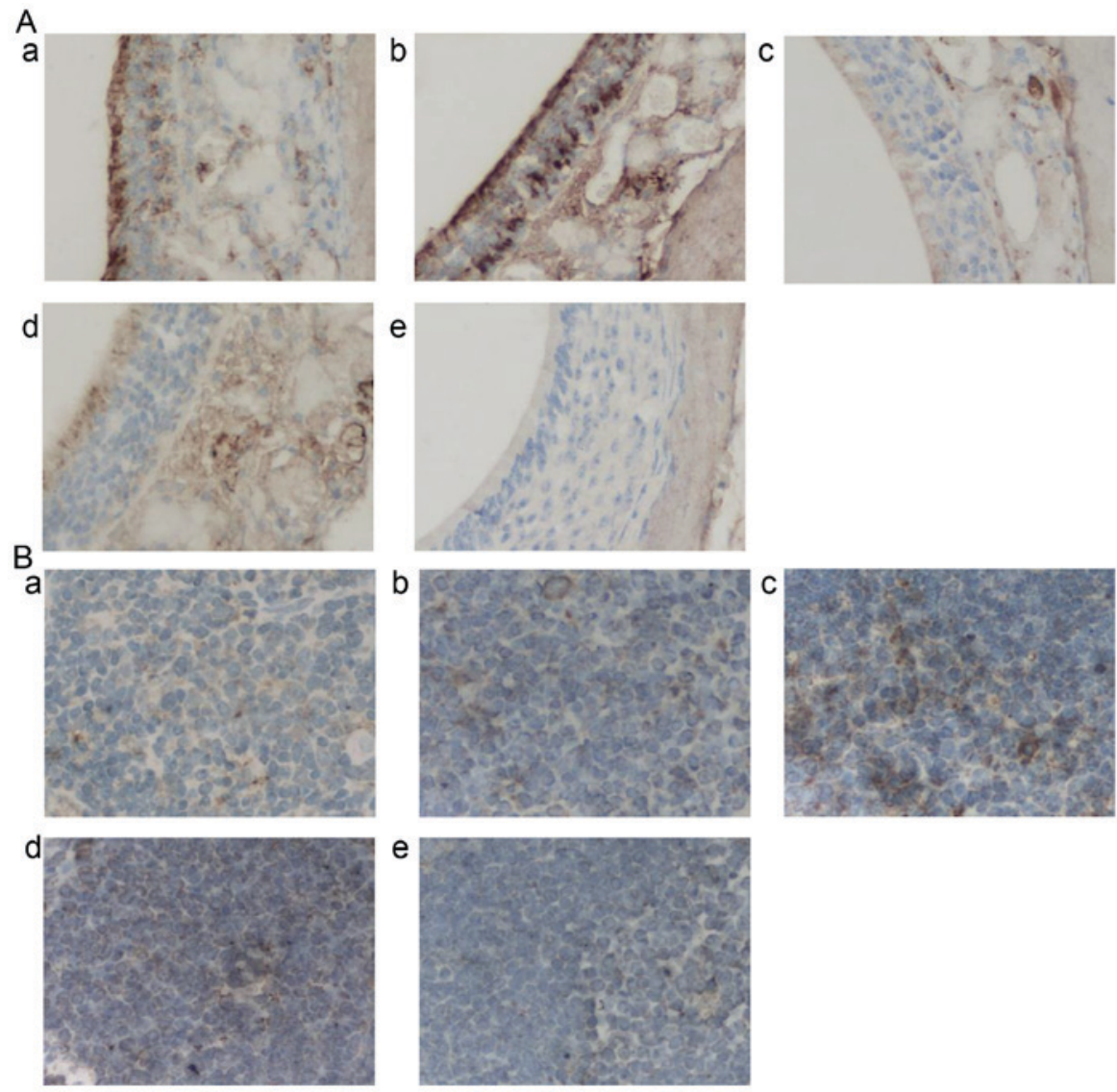

Figure 6. Effects of AST administration on Foxp3 protein expression. (A) Representative photomicrographs of Foxp3 protein expression in nasal mucosa tissue samples in the (a) normal, (b) $25 \mathrm{mg} / \mathrm{kg}$ AST, (c) $50 \mathrm{mg} / \mathrm{kg}$ AST, (d) DEX and (e) OVA groups. (B) Representative photomicrographs of mouse spleen tissue in the (a) normal, (b) $25 \mathrm{mg} / \mathrm{kg}$ AST, (c) $50 \mathrm{mg} / \mathrm{kg}$ AST, (d) DEX and (e) OVA groups. Magnification, x400. AST, Astragaloside IV; OVA, ovalbumin; DEX, dexamethasone; T-bet, Foxp 3, forkhead box protein 3.

however, the expression of GATA-3 has been demonstrated to be markedly upregulated in cells differentiating along the Th2 lineage, and downregulated in cells differentiating along the Th1 pathway $(33,34)$. The present study revealed that in mice with OVA-induced allergic rhinitis, GATA-3 expression was markedly upregulated in nasal mucosal and spleen tissue compared with normal mice. Notably, GATA-3 expression levels were markedly decreased following treatment with AST. Conversely, T-bet levels were upregulated following AST administration in OVA-induced allergic mice. T-bet is 

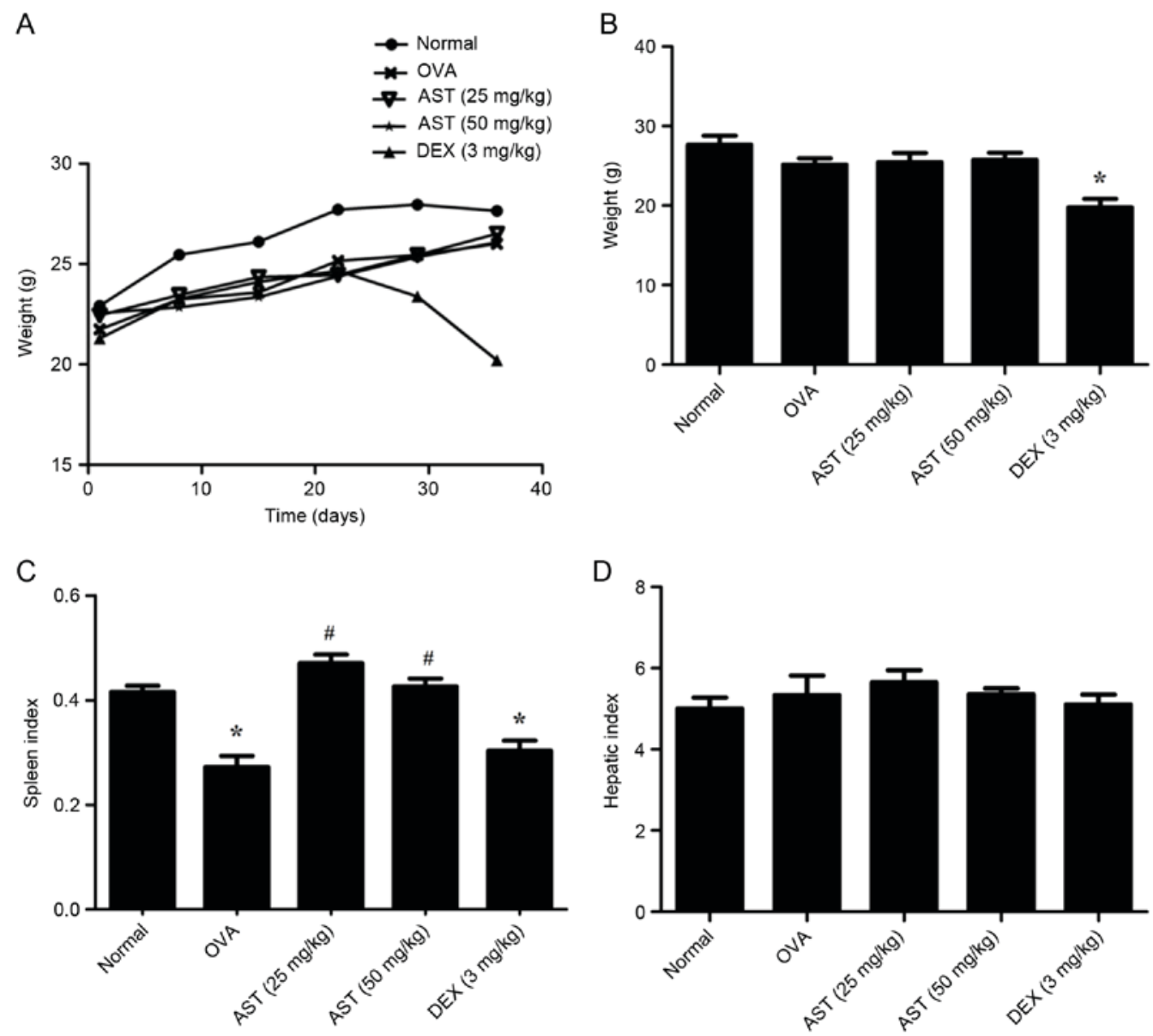

Figure 7. Adverse effects of DEX were assessed based on weight measurements and the spleen and liver indices of allergic mice. (A) Body weight variation in mice belonging to all treatment groups, assessed weekly using an electronic scale. (B) Mouse body weight measured $48 \mathrm{~h}$ following the administration of the last treatment. (C) Spleen and (D) hepatic indices were calculated. Data are expressed as the mean \pm standard deviation. ${ }^{*} \mathrm{P}<0.05$ vs. normal; ${ }^{\# P} \mathrm{P}<0.05$ vs. OVA. DEX, dexamethasone; OVA, ovalbumin; AST, Astragaloside IV.

a member of the T-box family of transcription factors that has been revealed to serve a critical role in the regulation of Th1-lineage commitment (35). The present findings suggested that the expression of GATA-3 and T-bet may be altered during allergic immune responses and may be implicated in the regulation of $\mathrm{Th} 1 / \mathrm{Th} 2$ differentiation.

Treg and Th17 cells have been identified as two Th cell subtypes independent from Th1 and Th2, that serve opposing roles in vivo (36). Tregs have been reported to inhibit inflammatory and allergic responses, and exert crucial functions in autoimmunity and immunological tolerance. Tregs expressing the transcription factor Foxp3 have been demonstrated to possess anti-inflammatory properties and to be involved in the maintenance of immunological tolerance under physiological conditions (7). In addition, previous studies have reported that $\mathrm{CD} 25^{\text {hi }}$ Foxp $^{+}$Tregs were able to effectively suppress Th2-mediated responses to allergens in health, whereas this effect was abolished in atopic allergic diseases $(37,38)$. The present study revealed that treatment with AST markedly upregulated Foxp3 levels in nasal mucosal and spleen tissue compared with allergic untreated mice.

ROR $\gamma t$ is a splice variant of ROR, which has been identified as an essential factor during Th17 cellular differentiation. Following the retroviral vector-mediated transduction of
ROR $\gamma$ t into naive $\mathrm{T}$ cells, Th17 cell development was enhanced, therefore suggesting that ROR $\gamma$ t may be essential for Th17 cellular proliferation (9). The induction of ROR $\gamma t$ has been reported to be dependent on the activity of STAT-3. Chromatin immunoprecipitation analysis demonstrated that STAT-3 was able to directly bind the IL-17A promoter, thus suggesting that ROR $\gamma$ t and STAT-3 may collaboratively regulate the transcriptional profile of Th17 cells (10). The present study revealed that the protein expression of STAT-3 and the mRNA expression of ROR $\gamma$ t were downregulated following AST administration in vivo.

DEX and AST were demonstrated to exert similar effects on OVA-induced allergic rhinitis; however, the weight and the spleen index of mice receiving long-term treatment with DEX was significantly reduced, suggesting that AST treatment may have fewer side effects compared with the traditional anti-allergic agent DEX.

In conclusion, the results of the present study suggested that treatment with AST may alleviate the symptoms of OVA-induced allergic rhinitis, potentially by mediating the Th1/Th2 cell balance, via regulating the expression levels of T-bet, GATA-3, Foxp3 and ROR $\gamma$ t. Therefore, AST may represent an alternative therapeutic approach for the treatment of patients with allergic rhinitis. 


\section{Acknowledgements}

The present study was supported by the Health Bureau Cooperation Project of Chongqing (grant no. 20142042) and the Science and Technology Project of Yuzhong District, Chongqing (grant no. 20140123).

The authors of the present study would like to acknowledge the College of Life Science (Chongqing Medical University, Chongqing, China) for their technical support.

\section{References}

1. Adamia N, Jorjoliani L, Khachapuridze D, Katamadze N and Chkuaseli N: Allergic diseases and asthma in adolescents. Georgian Med News: 58-62, 2015.

2. Gotoh M: Allergen immunotherapy for allergic rhinitis. Arerugi 64: 693-699, 2015 (In Japanese).

3. Ma C, Ma Z, Liao XL, Liu J, Fu Q and Ma S: Immunoregulatory effects of glycyrrhizic acid exerts anti-asthmatic effects via modulation of Th1/Th2 cytokines and enhancement of CD4(+) CD25(+)Foxp3+ regulatory $\mathrm{T}$ cells in ovalbumin-sensitized mice. J Ethnopharmacol 148: 755-762, 2013.

4. Ku CJ, Lim KC, Kalantry S, Maillard I, Engel JD and Hosoya T: A monoallelic-to-biallelic T-cell transcriptional switch regulates GATA3 abundance. Genes Dev 29: 1930-1941, 2015.

5. Han LN, Guo SL, Li TL, Ding GL, Zhang YJ and Ma JL: Effect of immune modulation therapy on cardiac function and T-bet/GATA-3 gene expression in aging male patients with chronic cardiac insufficiency. Immunotherapy 5: 143-153, 2013.

6. Sanchez AM, Zhu J, Huang X and Yang Y: The development and function of memory regulatory $\mathrm{T}$ cells after acute viral infections. J Immunol 189: 2805-2814, 2012.

7. Lloyd CM and Hawrylowicz CM: Regulatory T cells in asthma. Immunity 31: 438-449, 2009.

8. Chen Z, Lin F, Gao Y, Li Z, Zhang J, Xing Y, Deng Z, Yao Z, Tsun A and Li B: FOXP3 and ROR $\gamma$ t: Transcriptional regulation of Treg and Th17. Int Immunopharmacol 11: 536-542, 2011.

9. Korn T, Bettelli E, Oukka M and Kuchroo VK: IL-17 and Th17 cells. Annu Rev Immunol 27: 485-517, 2009.

10. Yang XO, Panopoulos AD, Nurieva R, Chang SH, Wang D, Watowich SS and Dong C: STAT3 regulates cytokine-mediated generation of inflammatory helper T cells. J Biol Chem 282: 9358-9363, 2007.

11. Guo H and Liu MP: Mechanism of traditional Chinese medicine in the treatment of allergic rhinitis. Chin Med J (Engl) 126: 756-760, 2013.

12. Wang B and Chen MZ: Astragaloside IV possesses antiarthritic effect by preventing interleukin $1 \beta$-induced joint inflammation and cartilage damage. Arch Pharm Res 37: 793-802, 2014.

13. Huang LF, Yao YM, Li JF, Zhang SW, Li WX, Dong N, Yu Y and Sheng ZY: The effect of Astragaloside IV on immune function of regulatory $\mathrm{T}$ cell mediated by high mobility group box 1 protein in vitro. Fitoterapia 83: 1514-1522, 2012.

14. Qiu YY,Zhu JX, Bian T, Gao F, Qian XF, Du Q, Yuan MY, Sun H, Shi LZ and Yu MH: Protective effects of astragaloside IV against ovalbumin-induced lung inflammation are regulated/mediated by T-bet/GATA-3. Pharmacology 94: 51-59, 2014.

15. Zhao J, Yang P, Li F, Tao L, Ding H, Rui Y, Cao Z and Zhang W: Therapeutic effects of astragaloside IV on myocardial injuries: Multi-target identification and network analysis. PLoS One 7: e44938, 2012.

16. Li M, Qu YZ, Zhao ZW, Wu SX, Liu YY, Wei XY, Gao L and Gao GD: Astragaloside IV protects against focal cerebral ischemia/reperfusion injury correlating to suppression of neutrophils adhesion-related molecules. Neurochem Int 60: 458-465, 2012.

17. Chen SM, Tsai YS, Lee SW, Liu YH, Liao SK, Chang WW and Tsai PJ: Astragalus membranaceus modulates Th1/2 immune balance and activates PPAR $\gamma$ in a murine asthma model. Biochem Cell Biol 92: 397-405, 2014.

18. Hiromura Y, Kishida T, Nakano H, Hama T, Imanishi J, Hisa Y and Mazda O: IL-21 administration into the nostril alleviates murine allergic rhinitis. J Immunol 179: 7157-7165, 2007.
19. Dao-jun X: Studies on the effects of Freud's adjuvant and aluminum hydroxide adjuvant on Tregs and $\mathrm{CD} 4^{+} \mathrm{T}$ cell relative genes in spleen of mice ( $\mathrm{PhD}$ thesis). Hunan Agricultural University, 2010 (in Chinese).

20. Livak KJ and Schmittgen TD: Analysis of relative gene expression data using real-time quantitative PCR and the 2(-Delta Delta C(T)) Method: Methods 25: 402-408, 2001.

21. Chen SM, Tsai YS, Lee SW, Liu YH, Liao SK, Chang WW and Tsai PJ: Astragalus membranaceus modulates Th1/2 immune balance and activates PPAR $\gamma$ in a murine asthma model. Biochem Cell Biol 92: 397-405, 2014.

22. Mandhane SN, Shah JH and Thennati R: Allergic rhinitis: An update on disease, present treatments and future prospects. Int Immunopharmacol 11: 1646-1662, 2011.

23. Shen J, Ke X, Hong S, Zeng Q, Liang C, Li T and Tang A: Epidemiological features of allergic rhinitis in four major cities in western China. J Huazhong Univ Sci Technolog Med Sci 31: 433-440, 2011.

24. Eid N, Morton R, Olds B, Clark P, Sheikh S and Looney S: Decreased morning serum cortisol levels in children with asthma treated with inhaled fluticasone propionate. Pediatrics 109: 217-221, 2002.

25. Klimek L, Mullol J, Hellings P, Gevaert P, Mösges R and Fokkens W: Recent pharmacological developments in the treatment of perennial and persistent allergic rhinitis. Expert Opin Pharmacother 17: 657-669, 2016.

26. Keith PK, Koch C, Djandji M, Bouchard J, Psaradellis E, Sampalis JS, Schellenberg RR and McIvor RA: Montelukast as add-on therapy with inhaled corticosteroids alone or inhaled corticosteroids and long-acting beta-2-agonists in the management of patients diagnosed with asthma and concurrent allergic rhinitis (the RADAR trial). Can Respir J 16 (Suppl A): 17A-31A, 2009 (In English, French).

27. Jin HL, W LM, Luo QL, Li B, Du YJ, Lv YB and Dong JC: Effects of astragaloside IV on Th2 lymphocyte D 10. G 4.1 in vitro. Chinese Pharmacological Bulletin 30: 1508-1513, 2014 (in Chinese).

28. Juneja L and Parmar HS: Ovalbumin induced allergic rhinitis and development of prediabetes to rats: Possible role of Th2 cytokines. Inflamm Allergy Drug Targets 12: 199-205, 2013.

29. Takhar P, Smurthwaite L, Coker HA, Fear DJ, Banfield GK, Carr VA, Durham SR and Gould HJ: Allergen drives class switching to IgE in the nasal mucosa in allergic rhinitis. J Immunol 174: 5024-5032, 2005.

30. Shang XZ, Armstrong J, Yang GY, Volk A, Li J, Griswold DE, Emmell E and Li L: Regulation of antigen-specific versus by-stander IgE production after antigen sensitization. Cell Immunol 229: 106-116, 2004.

31. Melli LC, do Carmo-Rodrigues MS, Araújo-Filho HB, Solé D and de Morais MB: Intestinal microbiota and allergic diseases: A systematic review. Allergol Immunopathol (Madr) 44: 177-188, 2016.

32. Nogueira JC and Goncalves Mda C: Probiotics in allergic rhinitis. Braz J Otorhinolaryngol 77: 129-134, 2011 (In Portuguese).

33. Ouyang W, Ranganath SH, Weindel K, Bhattacharya D, Murphy TL, Sha WC and Murphy KM: Inhibition of Th1 development mediated by GATA-3 through an IL-4-independent mechanism. Immunity 9: 745-755, 1998.

34. Zhang DH, Cohn L, Ray P, Bottomly K and Ray A: Transcription factor GATA-3 is differentially expressed in murine Th1 and Th2 cells and controls Th2-specific expression of the interleukin-5 gene. J Biol Chem 272: 21597-21603, 1997.

35. Szabo SJ, Kim ST, Costa GL, Zhang X, Fathman CG and Glimcher LH: Pillars article: A novel transcription factor, T-bet, directs Th1 lineage commitment. Cell. 2000. 100: 655-669. J Immunol 194: 2961-2975, 2015.

36. Chen Z, Lin F, Gao Y, Li Z, Zhang J, Xing Y, Deng Z, Yao Z, Tsun A and Li B: FOXP3 and ROR $\gamma \mathrm{t}$ : Transcriptional regulation of treg and Th17. Int Immunopharmacol 11: 536-542, 2011.

37. Kündig TM and Bachmann MF: Allergen-specific immunotherapy: Regulatory $\mathrm{T}$ cells or allergen-specific IgG? Hum Vaccin 6: 673-675, 2010.

38. Nouri-Aria KT and Durham SR: Regulatory T cells and allergic disease. Inflamm Allergy Drug Targets 7: 237-252, 2008. 